\title{
Fluorine F-18 ML-10
}

National Cancer Institute

\section{Source}

National Cancer Institute. Fluorine F-18 ML-10. NCI Thesaurus. Code C78468.

A small molecular-weight, malonic acid-based probe [(2-(5-fluoro-pentyl)-2-methylmalonic acid or ML-10] labeled with the radioactive isotope fluorine $F 18$ with potential apoptosis radioimaging use. Upon administration, [F18]-ML-10 binds selectively to apoptotic cells due to apoptotic cell membrane features that differ from those of normal, healthy and necrotic cell membranes. Upon entering the apoptotic cell, this agent accumulates within the cytoplasm where it can be imaged using positron emission tomography (PET). Detection of apoptotic cells using this imaging technology may be useful in monitoring tumor responses to cytotoxic therapies. ML-10 appears to mimic the alkyl-malonic acid motif present in gamma -carboxyglutamic (Gla), an amino acid that plays a crucial role in the binding of clotting factors to negatively-charged phospholipids exposed on the surfaces of apoptotic cells. 